\title{
Mortalidade por Cancro do Pulmão
}

\author{
Lung Cancer Mortality
}

\author{
Renato SOTTO-MAYOR ${ }^{1,2,3}$ \\ Acta Med Port 2014 Jan-Feb;27(1):9-11
}

Palavras-chave: Detecção Precoce do Cancro; Neoplasias do Pulmão/diagnóstico; Neoplasias do Pulmão/mortalidade; Rastreio.

Keywords: Early Detection of Cancer; Lung Neoplasms/diagnosis; Lung Neoplasms/mortality.

O cancro do pulmão, considerado uma tísica cancerosa por Bayle, no início do século XIX (1810), e descrito por René Laënnec (1819) como um encéphaloïde du poumon, era uma entidade clínica rara no começo do século passado. ${ }^{1}$

Contudo, com o incremento do tabagismo (o seu fator etiológico major) que veio a verificar-se desde então, o cancro do pulmão tornou-se uma verdadeira epidemia global sendo atualmente a neoplasia maligna mais frequente a nível mundial, responsável anualmente por 13\% (1 600 000) dos novos casos de cancro e de 18\% (1 400 000) das causas de morte por essa patologia. ${ }^{2}$

No que se refere ao cancro em geral, nos homens, o do pulmão é o mais diagnosticado ( $17 \%$ dos novos casos) e o que apresenta maior mortalidade ( $23 \%$ dos óbitos), enquanto nas mulheres, onde esses lugares são ocupados pelo cancro da mama, o do pulmão situa-se, respetivamente, no quarto ( $9 \%$ dos novos casos) e no segundo $(13 \%$ dos óbitos), ${ }^{2}$ dados que variam (Tabela 1) de acordo com o grau de desenvolvimento e o estádio de epidemia tabágica da área geográfica em estudo, prevendo-se que, em zonas desenvolvidas como a Europa e a América do Norte, se torne, num futuro próximo, a primeira causa de morte por cancro na mulher. ${ }^{3-5}$

Quanto às taxas de sobrevivência global aos cinco anos, dos doentes com cancro do pulmão, a melhoria tem-se mostrado muito lenta tendo evoluído de 13\% em 1975 para $16 \%$ nos últimos dados publicados, ${ }^{6}$ sendo $18 \%$ na mulher e $14 \%$ no homem, o que corresponde a um ganho de $1 \%$ em cada década nos últimos 30 anos, valores que ainda se encontram muito aquém dos alcançados com outros tumores malignos como os da próstata (99\%), da tiroideia $(97 \%)$, do testículo (96\%), da mama feminina $(89 \%)$ ou da globalidade dos cancros (66\%), mas que não são de menosprezar pois significam que mais de 250000 doentes estarão vivos ao fim desse período de tempo.

O mau prognóstico dos doentes com cancro do pulmão deve-se ao facto do seu diagnóstico se fazer, numa elevada percentagem dos casos, numa fase tardia da história natural da doença, sabendo-se que, nos carcinomas pulmonares de não pequenas células ( $85 \%$ dos diagnósticos), a sua apresentação clínica e imagiológica ocorre nos estádios III e IV em $80 \%$ das situações (estádios I:10\%, II:9\%, III:21\%, IV:60\%) e que nos carcinomas pulmonares de pequenas células (15\% dos diagnósticos) a doença limitada dá-se em $30 \%$ dos doentes e a doença extensa em $70 \%$, com sobrevivências globais sucessivamente menores à medida que o estádio TNM se agrava, pelo que, nos primeiros, só se encontram vivos a um ano $42 \%$ dos doentes e $16 \%$ aos cinco anos (sobrevivências globais aos cinco anos, segundo os estádios, de 50\%/IA, 43\%/IB, 36\%/IIA, 25\%/IIB, 19\%/IIIA, $7 \% /$ IIIB e $4 \% / \mathrm{IV}),{ }^{7}$ enquanto nos carcinomas pulmonares de pequenas células a sobrevivência global aos cinco anos é de $14 \%$ na doença limitada e de $0-1 \%$ na doença extensa. ${ }^{8}$

Face aos dados apresentados, em que o cancro do pulmão ocupa uma das principais causas de mortalidade no Mundo, torna-se prioritário reverter este flagelo, implementando e reforçando todas as medidas que levem à redução do risco pela suspensão do hábito tabágico e pela proteção dos não fumadores face ao fumo do tabaco (tabagismo passivo), pela salvaguarda de outros fatores de risco nos fumadores e em não fumadores, quer a nível ambiental como laboral, pela definição de uma estratégia que permita, no terreno, o seu diagnóstico precoce, numa fase ainda assintomática, e por uma política que possibilite a cada cidadão um fácil acesso aos serviços de saúde de modo que se investiguem atempadamente quaisquer sinais de alerta da doença.

Desde longa data, têm-se estudado várias estratégias de rastreio do cancro do pulmão no sentido de alcançar o seu diagnóstico precoce mas, apesar de algumas apontarem para benefícios pontuais, nenhuma demonstrou vantagens em termos de diminuição da mortalidade.

Com a publicação dos resultados do National Lung Screening Trial, que teve o apoio do National Cancer Insti-

\footnotetext{
1. Serviço de Pneumologia. Hospital Pulido Valente. Centro Hospitalar Lisboa Norte. Lisboa. Portugal.

2. Hospital de Dia de Pneumologia Oncológica. Hospital Pulido Valente. Centro Hospitalar Lisboa Norte. Lisboa. Portugal.

3. Faculdade de Medicina. Universidade de Lisboa. Lisboa. Portugal.

Recebido: 25 de Setembro de 2013 - Aceite: 28 de Setembro de 2013 | Copyright @ Ordem dos Médicos 2014
} 
Tabela 1 - Incidência e mortalidade por cancro do pulmão no Mundo, na Europa e em Portugal: Posicionamento relativo segundo os géneros (GLOBOCAN, IARC/WHO- 2008). ${ }^{2}$

Cancro do pulmão no Mundo

\begin{tabular}{|c|c|c|}
\hline Incidência & $1^{\circ} \mathrm{H}$ & $\begin{array}{l}\text { Ambos os géneros: } 3^{\circ} \\
\text { (> } 1600 \text { 000/ano) }\end{array}$ \\
\hline Mortalidade & $1^{\circ} \mathrm{H}$ & $\begin{array}{l}\text { Ambos os géneros: } 1^{\circ} \\
\text { (85\% da incidência) }\end{array}$ \\
\hline \multicolumn{3}{|c|}{ Cancro do pulmão na Europa } \\
\hline & EU 25 & Portugal \\
\hline Incidência & $\begin{array}{l}3^{\circ} \mathrm{H} \quad 8^{\circ} \mathrm{M} \\
\text { Ambos os géneros: } 4^{\circ} \\
(3 \mathrm{H}: 1 \mathrm{M})\end{array}$ & $\begin{array}{l}3^{\circ} \mathrm{H} \quad 7^{\circ} \mathrm{M} \\
\text { Ambos os géneros: } 4^{\circ} \\
(4 \mathrm{H}: 1 \mathrm{M})\end{array}$ \\
\hline Mortalidade & $\begin{array}{l}1^{\circ} \mathrm{H} \quad 2^{\circ} \mathrm{M} \\
\text { Ambos os géneros: } 1^{\circ}\end{array}$ & $\begin{array}{l}1^{\circ} \mathrm{H} \quad 4^{\circ} \mathrm{M} \\
\text { Ambos os géneros: } 2^{\circ} \\
(n=3681)^{\star}\end{array}$ \\
\hline
\end{tabular}

tute, foi alcançado um novo paradigma no que se refere ao rastreio destes tumores malignos. ${ }^{9}$

O estudo, que decorreu de 2002 a 2007, incidiu sobre uma população com idades compreendidas entre os 55 e 74 anos, fumadores ou ex-fumadores (nos últimos 15 anos), com uma carga tabágica igual ou superior a 30 UMA; foram randomizados ( $n=53454$ ) em iguais proporções (1:1) para a realização de TC espiral de baixa dose do tórax, com frequência anual, durante três anos consecutivos, ou para telerradiografia do tórax PA com igual intervalo, ficando os dois grupos em follow-up por mais três anos.

No que fez TC encontrou-se uma diminuição de mortalidade por cancro do pulmão de $20 \%$ em relação ao da telerradiografia (e de $7 \%$ por todas as causas) o que, estatisticamente, foi bastante significativo, e nunca antes alcançado, sendo necessários 320 exames por TC para prevenir uma morte por cancro do pulmão.

Os resultados referem-se a uma população bem definida, de alto risco para o cancro do pulmão e potencial candidata a cirurgia, não se aplicando necessariamente a não fumadores, a indivíduos mais jovens, debilitados, ou mais velhos que não possam beneficiar de atitudes terapêuticas curativas.

Com o presente estudo, ${ }^{9}$ abriu-se uma janela de oportunidade para o rastreio do cancro do pulmão em fase precoce, mas levantam-se alguns problemas que se prendem, por exemplo, com o elevado número de lesões encontradas, que necessitam de investigação complementar e que se revelam benignas, a carga emocional que esse facto acarreta, os custos inerentes ao rastreio, se o mesmo deverá ser alargado a outros grupos de populações alvo, o facto de fumadores submetidos ao rastreio sentirem-se motivados para continuarem a fumar em face de uma TC negativa, os eventuais riscos a longo termo das radiações, a necessidade de definir a frequência com que os exames imagiológicos deverão ser realizados e como monitorizar o follow-up dos rastreados.

Existe a necessidade de consolidar os benefícios e de caracterizar os eventuais riscos desta abordagem, a qual deve ter como base centros com imagiologia de alta qualidade e em que seja possível ter uma equipa multidisciplinar que integre imagiologistas, patologistas, pneumologistas e cirurgiões torácicos de referência.

Tem-se realizado um debate alargado no sentido de atingir um consenso sobre o valor do rastreio por TC helicoidal de baixa dose em populações de risco como é a dos grandes fumadores, sendo importante que se avaliem os custos-benefícios que acompanham a sua eventual implementação no terreno. ${ }^{10}$

Com base nesses debates, diferentes sociedades científicas americanas e europeias têm elaborado documentos em que se descrevem os fatores de risco para o cancro do pulmão, recomendam critérios de seleção dos indivíduos de alto risco que deverão ser rastreados, fornecem recomendações para a avaliação e o follow-up dos nódulos pulmonares encontrados na sequência dos rastreios, discutem a acuidade da TC helicoidal de baixa dose, o tipo de imagens encontradas e como devem ser valorizadas, e apontam os benefícios e os riscos desta abordagem, realçando que a sua efetivação deve ser articulada com um plano bem estruturado de luta anti-tabágica pois em nenhuma circunstância existe um nível de segurança de exposição ao fumo do tabaco.

\section{CONFLITO DE INTERESSES}

O autor declara que não houve conflito de interesses na realização deste trabalho.

\section{FONTES DE FINANCIAMENTO}

O autor declara a inexistência de fontes de financiamento externas. 


\section{REFERÊNCIAS}

1. Sotto-Mayor R. Marcos históricos no estudo do cancro do pulmão. Rev Port Pneumol. 2006;12:401-46.

2. Jemal A, Bray F, Center MM, Ferlay J, Ward E, Forman D. Global cancer statistics. CA Cancer J Clin. 2011;61:69-90.

3. Youlden DR, Cramb SM, Baade PD. The international epidemiology of lung Cancer: Geographical distribution and secular trends. J Thorac Oncol. 2008;3:819-31.

4. Bray F, Jemal A, Grey N, Ferlay J, Forman D. Global cancer transitions according to the human development index (2008-2030): a populationbased study. Lancet Oncol. 2012;13:790-801.

5. Malvezzi M, Bertuccio P, Levi F, La Vecchia C, Negri E. European cancer mortality predictions for the year 2013. Ann Oncol. 2013;24:792-800.

6. Petrelli NJ, Winer EP, Brahmer J, Dubey S, Smith S, Thomas C, et al. Clinical cancer advances 2009: Major research advances in cancer treatment, prevention, and screening - A report from the American Soci- ety of Clinical Oncology. J Clin Oncol. 2009;27:6052-69.

7. Groome PA, Bolejack V, Crowley JJ, Kennedy C, Krasnik M, Sobin LH, et al. The IASLC lung cancer staging project: Validation of the proposals for revision of the $\mathrm{T}, \mathrm{N}$, and $\mathrm{M}$ descriptors and consequent stage groupings in the forthcoming (seventh) edition of the TNM classification of malignant tumours. J Thorac Oncol. 2007;2:694-705.

8. Huber RM, Tufman A. Update on small cell lung cancer management. Breath. 2012;8:315-30.

9. The National Lung Screening Trial Research Team. Reduced lung-cancer mortality with low-dose computed tomographic screening. N Engl J Med. 2011;365:395-409.

10. Humphrey L, Deffebach M, Pappas M, Baumann C, Artis K, Mitchell JP, et al. Screening for lung cancer with low-dose computed tomography: A systematic review to update the US Preventive Services Task Force Recommendation. Ann Intern Med. 2013;159:411-20. 


\section{Mortalidade por Cancro do Pulmão}

Acta Med Port 2014:27:9-11

Publicado pela Acta Médica Portuguesa, a Revista Científica da Ordem dos Médicos

Av. Almirante Gago Coutinho, 151

1749-084 Lisboa, Portugal.

Tel: +351218428 215

E-mail: submissao@actamedicaportuguesa.com

www.actamedicaportuguesa.com

ISSN:0870-399X | e-ISSN: 1646-0758

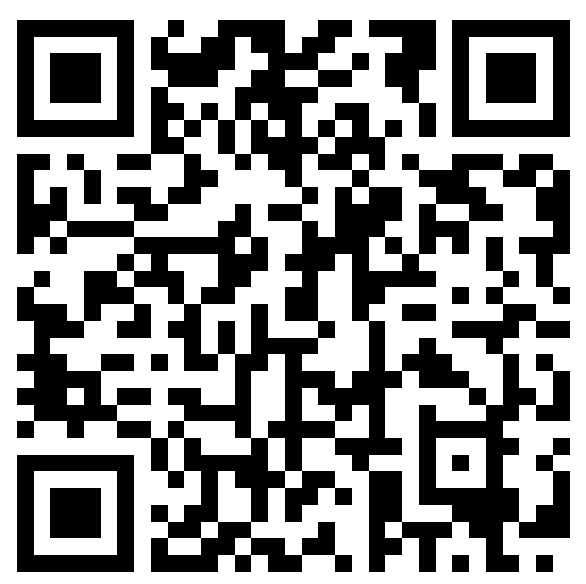

